\title{
Artificial Macropores with Sandy Fillings Enhance Desalinization and Increase Plant Biomass in Two Contrasting Salt-Affected Soils
}

\author{
Yifu Zhang ${ }^{1, *(\mathbb{D}, \text { Ruihong Zhang }}{ }^{1,2}$, Baofeng Zhang ${ }^{1}$ and Xiaobo $\mathrm{Xi}^{1}{ }^{1}$ \\ 1 School of Mechanical Engineering, Yangzhou University, Yangzhou 225127, China; 002674@yzu.edu.cn (R.Z.); \\ bf_zhang@yzu.edu.cn (B.Z.); xbxi@yzu.edu.cn (X.X.) \\ 2 Jiangsu Engineering Center for Modern Agricultural Machinery and Agronomy Technology, \\ Yangzhou 225127, China \\ * Correspondence: zyfu@yzu.edu.cn; Tel.: +86-0514-87971858
}

check for

updates

Citation: Zhang, Y.; Zhang, R.; Zhang, B.; Xi, X. Artificial Macropores with Sandy Fillings Enhance

Desalinization and Increase Plant Biomass in Two Contrasting Salt-Affected Soils. Appl. Sci. 2021, 11, 3037. https://doi.org/10.3390/ app11073037

Academic Editors: David Zumr and Daniel Dias

Received: 24 January 2021

Accepted: 18 March 2021

Published: 29 March 2021

Publisher's Note: MDPI stays neutra with regard to jurisdictional claims in published maps and institutional affiliations.

Copyright: (C) 2021 by the authors Licensee MDPI, Basel, Switzerland. This article is an open access article distributed under the terms and conditions of the Creative Commons Attribution (CC BY) license (https:// creativecommons.org/licenses/by/ $4.0 /)$

\begin{abstract}
Salt accumulation in topsoil is a widespread restricting factor that limits agricultural production and threatens food security in arid and semi-arid regions. However, whether this upward enrichment was suppressed by macropores was less documented. Therefore, artificial macropores with sandy fillings (AMSF) method was proposed in this study. Soil column experiments showed a significant improvement of saturated hydraulic conductivity $(K s)$ by more than $260 \%$ under artificial macropore treatment. Freshwater irrigation was conducted to monitor the short-term water and salt movement. This research aimed at evaluating the potential benefit of AMSF method on soil desalinization in coastal farmland of northern China. The results demonstrated that downward movement of soil water was stimulated in AMSF method, accordingly, washing more salt ions out of top rooting zone. Particularly, $10 \mathrm{~cm}$ or more macropore depth treatments of AMSF method enhanced total desalinization by $52.1 \%$ to $176.6 \%$ in $0-30 \mathrm{~cm}$ soil layer, in comparison to the control group without macropore. Subsequent observations for alfalfa showed higher biomass by $20.8 \%$ under $15 \mathrm{~cm}$ macropore depth. The results here provided an exploration demonstration to pursue these studies with the ultimate goal of optimizing application strategies for amendment in coastal salt-affected lands of northern China.
\end{abstract}

Keywords: macropores; sandy fillings; infiltration; soil desalinization; freshwater irrigation

\section{Introduction}

Soil salinization is a global widespread problem, which would limit agricultural production and threaten food security dramatically in arid and semi-arid regions $[1,2]$. According to statistics, salt-affected soils account for approximately $25 \%$ of the total land area, widely distributing in over 100 countries around the world [3].

Salt accumulation has detrimental influence on soil physicochemical properties and crop growth as well. This upward movement of salt is caused by the combined influence of groundwater transport, soil evapotranspiration and other water input. The groundwater which contains soluble salt tends to transport via capillary rise to upper soil layer due to continuous evapotranspiration [4]. Simultaneously, liquid water also moves up to compensate for the water loss, and thereby, salt accumulates and precipitates in topsoil. The solid salt may also occupy the pore between soil particles and thereby weaken soil porosity. More importantly, the vast majority of crops' roots concentrate in the top 0 to $30 \mathrm{~cm}$ soil layer [5], so it is of great importance to ensure an acceptable salt conditions in the topsoil for realizing regional agro-ecological value.

Macropores are continuous pores with over $0.05 \mathrm{~mm}$ diameter, which naturally exist in the form of root channels, wormholes, or soil aggregate gaps. The irregular structure makes it complicated and difficult to conduct accurate infiltration simulation [6]. However, macropores have been considered as a key element to support water flow because they usually work as a water pathway that preferentially delivers solutions into deeper layer $[7,8]$. 
More importantly, preferential flow under saturated condition tends to be dominated via macropores due to gravity [9]. This provides an important evidence of macropores for promoting soil infiltration. Therefore, artificial macropores were introduced into degraded lands for improving solute transport and bioremediation [10,11]. Aeration, another type of macropore, was tested to promote root penetration and soil environment in grass land $[12,13]$. Despite the positive paradigm in soil remediation, artificial macropores are merely a suboptimal option for exploiting ill-drained fields, as the empty macropore structure is difficult to maintain due to the collapse and clogging. Mori et al. [10] protected the macroporous structure by filling glass fibers, and doubled plant biomass was surveyed one year later. However, the enhanced infiltration may result from the capillary force which was produced by fibrous material.

In China, more than 36 million ha degraded lands are suffering from salt toxicity, among which coastal saline soils occupy significant proportion. Generally, coastal saline soils are vulnerable to climatic changes because of the intrusion from marine water and poor drainage capacity $[14,15]$. In this study, a novel solution was proposed to alleviate salt accumulation of coastal saline farmland. Specifically, we designed artificial macropores with sandy fillings (AMSF) method to determine how they contribute to water migration in saline soils, based on our hypothesis that if coastal lands with poor drainage capacity could be improved, it would be helpful in stimulating water downward transport, reducing salt accumulation, as well as thereby achieving an acceptable farmland. Therefore, column experiments were carried out to compare the drainage capacity of artificial macropore under different salinized levels; irrigation experiments with freshwater were conducted to monitor the water and salt movement, and alfalfa (Medicago sativa L.) was sown to observe plant growth.

Accordingly, the objective of this study was to create artificial macropores which filled with sandy material, to evaluate its potential benefits for salt-affected soils, and to thereby enhance soil infiltration, improve leach of topsoil with salt accumulation, and increase plant biomass.

\section{Materials and Methods}

\subsection{Field Experimental Site and Soils}

From June to August in 2016, field experiments were conducted at Shiji Tianyuan Agricultural Machinery Cooperative ( $\left.38^{\circ} 46^{\prime} \mathrm{N}, 117^{\circ} 13^{\prime} \mathrm{E}\right)$, located in Zhongtang town, Binhai district, Tianjin, China. The site is located in a warm and semi-humid region with a continental monsoon climate. Average annual temperature is $12.3^{\circ} \mathrm{C}$ with 211 frost-free days. Average annual rainfall is $570 \mathrm{~mm}$, which mostly falls between June and September.

In field plots, soil was classified as coastal solonchak, in accordance with Chinese grading standards of salinization. Two levels of salinized soil (mild and severe salinization) were selected. The soil chemical properties in top $30 \mathrm{~cm}$ were showed in Table 1.

\subsection{Design of Artificial Macropore with Sandy Fillings}

Previous studies have verified the advantage of artificial macropores in delivering solutes into deeper profile [16]. In this study, we attempted to improve surface desalinization for bare saline soils using artificial macropores (Figure 1). The artificial macropores were designed with following properties:(1) The artificial vertical boreholes with different depth were made to mimic macropore structure. (2) The fine sand particles, sandy material, were incorporated into artificial macropore to stabilize the structure. (3) The sandy particles generated a water pathway that delivered solution into deeper layer.

Meanwhile, we prepared sandy materials from sand dune outside the experimental sites. The texture was classified as fine sand, and its preparation steps were as follows: the sand sample was passed through a $1 \mathrm{~mm}$ sieve to separate gravel, then passed through $0.25-$ and $0.05-\mathrm{mm}$ sieve in turn, and finally mixed with $30 \%$ of medium and coarse sand ( 0.25 to $1 \mathrm{~mm})$, and $70 \%$ of fine sand $(0.05$ to $0.25 \mathrm{~mm})$ according to the USDA classification. Those cohesive particles with a size of less than $0.05 \mathrm{~mm}$ were removed. In this study, the 
upper apex of the filled material was $1 \mathrm{~cm}$ above the ground in order to relieve the clog or encrustation from soil particles during flooding [16]. In addition, the sands filled into holes cannot contain salt.

Table 1. Basic soil characteristics prior to the initiation of field experiments.

\begin{tabular}{|c|c|c|}
\hline \multirow{2}{*}{ Soil Properties } & \multicolumn{2}{|c|}{ Salinity Levels of Experimental Soil } \\
\hline & Mild Salinization & Severe Salinization \\
\hline \multicolumn{3}{|l|}{ Soil texture } \\
\hline Sand $(0.02 \sim 2 \mathrm{~mm}, \%)$ & 14.9 & 10.6 \\
\hline Silt (0.002 0.02 mm, \%) & 64.8 & 61.0 \\
\hline Clay $(<0.002 \mathrm{~mm}, \%)$ & 20.3 & 28.4 \\
\hline \multicolumn{3}{|l|}{ Soil physical properties } \\
\hline Bulk density $\left(\mathrm{g} \mathrm{cm}^{-3}\right)$ & 1.31 & 1.39 \\
\hline Total porosity $(\%)$ & 48.6 & 46.5 \\
\hline Field capacity (\%, by weight) & 24.7 & 28.4 \\
\hline \multicolumn{3}{|l|}{ Soil chemical properties } \\
\hline Electrical conductivity (1:5 soil to water, $\left.\mathrm{dS} \mathrm{m}^{-1}\right)$ & 0.56 & 2.04 \\
\hline Salt content $\left(\mathrm{g} \mathrm{kg}^{-1}\right)$ & 1.95 & 7.08 \\
\hline $\mathrm{pH}$ & 8.11 & 8.34 \\
\hline Organic matter $\left(\mathrm{g} \mathrm{kg}^{-1}\right)$ & 17.9 & 10.4 \\
\hline Available nitrogen $\left(\mathrm{mg} \mathrm{kg}^{-1}\right)$ & 55.6 & 64.5 \\
\hline Available phosphorus $\left(\mathrm{mg} \mathrm{kg}^{-1}\right)$ & 12.1 & 31.4 \\
\hline Available potassium $\left(\mathrm{mg} \mathrm{kg}^{-1}\right)$ & 97.8 & 63.2 \\
\hline
\end{tabular}
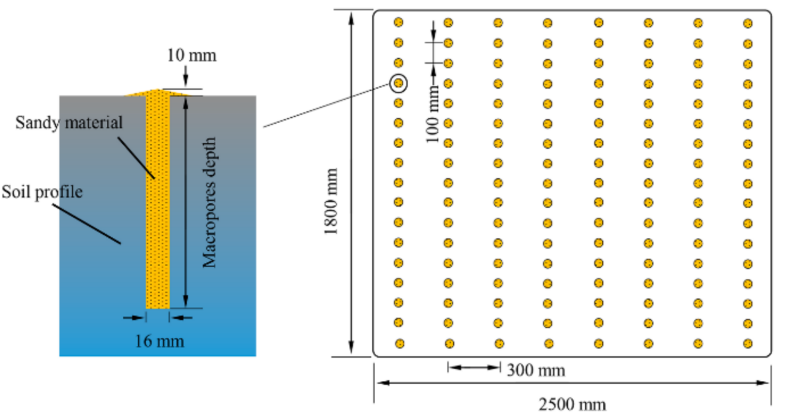

Figure 1. Schematic representation of artificial macropores with sandy fillings (AMSF) method.

\subsection{Field Irrigation Experiments}

Three different macropores depths $(5,10$ and $15 \mathrm{~cm})$ were introduced in these experiments. The treatment without artificial macropore $(0 \mathrm{~cm}$ depth treatment) was adopted as the control group. Three replicate plots were carried out for two salinization levels and four macropore treatments (twenty-four plots totally).

The vegetation was removed, and the surface was leveled prior to the experiment. Plots were $40 \mathrm{~cm}$ apart. Each plot was $2.5 \mathrm{~m}$ long and $1.8 \mathrm{~m}$ wide, around which 0.6 $\mathrm{m}$ depth plastic film was buried, and $15 \mathrm{~cm}$ high ridge was built to avoid lateral flow. Then total treatments were randomly separated, different deep artificial macropores were installed with $10 \mathrm{~cm}$ apart in a row, and the row distance was $30 \mathrm{~cm}$ (Figure 1). After that, freshwater was applied to reduce the salt interference from irrigation water, and the chemical properties are shown in Table 2. According to local irrigation practice, we introduced flood irrigation for each plot under $1200 \mathrm{~m}^{3} \mathrm{ha}^{-1}$, i.e., $0.54 \mathrm{~m}^{3}$ per plot.

Table 2. Chemical properties of irrigation water.

\begin{tabular}{ccccccccc}
\hline $\begin{array}{c}\text { Mineralization } \\
\left(\mathrm{g} \mathrm{L}^{-1}\right)\end{array}$ & $\begin{array}{c}\text { Total Salt } \\
\left(\mathrm{g} \mathrm{kg}^{-1}\right)\end{array}$ & $\begin{array}{c}\mathrm{HCO}_{3}^{-} \\
\left(\mathrm{g} \mathrm{L}^{-1}\right)\end{array}$ & $\begin{array}{c}\mathrm{Cl}^{-} \\
\left(\mathrm{g} \mathrm{L}^{-1}\right)\end{array}$ & $\begin{array}{c}\mathrm{SO}_{4}{ }^{2-} \\
\left(\mathrm{g} \mathrm{L}^{-1}\right)\end{array}$ & $\begin{array}{c}\mathrm{Ca}^{2+} \\
\left(\mathrm{g} \mathrm{L}^{-1}\right)\end{array}$ & $\begin{array}{c}\mathrm{Mg}^{2+} \\
\left(\mathrm{g} \mathrm{L}^{-1}\right)\end{array}$ & $\begin{array}{c}\mathrm{Na}^{+} \\
\left(\mathrm{g} \mathrm{L}^{-1}\right)\end{array}$ & $\begin{array}{c}\mathrm{K}^{+} \\
\left(\mathrm{g} \mathrm{L}^{-1}\right)\end{array}$ \\
\hline 0.192 & 0.250 & 0.116 & 0.039 & 0.010 & 0.024 & 0.048 & 0.009 & 0.004 \\
\hline
\end{tabular}




\subsection{Sampling and Measurements}

Soil samples were collected after 5, 10, 15, 20 and 25 days of irrigation, i.e., the duration of monitoring period was 25 days, referring to the research method of Li et al. [17]. More specifically, in each plot, soil samples were collected at $0 \sim 5 \mathrm{~cm}, 5 \sim 10 \mathrm{~cm}, 10 \sim 15 \mathrm{~cm}$, $15 \sim 20 \mathrm{~cm}, 20 \sim 30 \mathrm{~cm}, 30 \sim 40 \mathrm{~cm}, 40 \sim 50 \mathrm{~cm}$, and $50 \sim 60 \mathrm{~cm}$ depth. The metal ring samplers with $52 \mathrm{~mm}$ high and $70 \mathrm{~mm}$ in diameter were used to collect undisturbed soils. These ring samplers were hammered into the designed profile after the upper soils were collected and removed. No rainfall events were observed during the entire sampling period.

Undisturbed soils were randomly sampled to measure water content and bulk density based on oven drying method. Disturbed samples were collected with soil auger for salt determination. In addition, the macropores areas filled with sand were not included.

Soil moisture storage was estimated following the procedure described by He et al. [18]:

$$
W=10 \sum_{i=1}^{n} \theta_{\mathrm{g} i} \rho_{\mathrm{si}} z_{i} / \rho_{\mathrm{w}}
$$

where $W$ is soil moisture storage, $\mathrm{mm} ; \theta_{\mathrm{g} i}$ is soil gravimetric water content of $i$ soil layer, $\mathrm{g} \mathrm{g}^{-1} ; \rho_{\mathrm{s} i}$ is soil bulk density of $i$ soil layer, $\mathrm{g} \mathrm{cm}^{-3} ; z_{i}$ is thickness of $i$ soil layer, $\mathrm{cm} ; \rho_{\mathrm{w}}$ is density of water, $\mathrm{g} \mathrm{cm}^{-3}$.

The air-dried soil samples were pulverized and then passed through a $2 \mathrm{~mm}$ mesh sieve, while visible roots, pebbles and aggregates larger than $2 \mathrm{~mm}$ were screened out. Soil electrical conductivity was measured in a soil: water suspension (1:5) using an EC meter (DDS-11A, Shang Hai Yoke Instrument Co., Ltd., Shanghai City, China), and the soil salt content was calculated by an empirical equation, as described by Du et al. [19]:

$$
Y=3.471 E c+0.015 \ldots
$$

where $Y$ is soil salt content, $\mathrm{g} \mathrm{kg}^{-1}$; $E \mathrm{c}$ is conductivity of soil extract at $25^{\circ} \mathrm{C}, \mathrm{mS} \mathrm{cm}^{-1}$.

Soil salt storage was described as be the mass per unit area:

$$
S=10 \sum_{i=1}^{n} y_{i} \rho_{\mathrm{si}} z_{i}
$$

where $S$ is soil salt storage, $\mathrm{g} \mathrm{m}^{-2} ; y_{i}$ is soil salt content of $i$ soil layer, $\mathrm{g} \mathrm{kg}^{-1} ; \rho_{\mathrm{s} i}$ is soil bulk density of $i$ soil layer, $\mathrm{g} \mathrm{cm}^{-3} ; z_{i}$ is thickness of $i$ soil layer, $\mathrm{cm}$.

\subsection{Aboveground Plant Biomass}

After soil sampling, i.e., on the 26th day after irrigation, alfalfa (Medicago sativa L.) was planted manually at a rate of $15 \mathrm{~kg} \mathrm{ha}^{-1}$. Alfalfa seeds were drilled at a depth of $30 \mathrm{~mm}$ and a row spacing of $30 \mathrm{~cm}$. Chemical fertilizers $\left(\mathrm{N}^{-} \mathrm{P}_{2} \mathrm{O}_{5}-\mathrm{K}_{2} \mathrm{O}\right)$ were utilized simultaneously $40-50 \mathrm{~mm}$ below the seeds, to supply $85 \mathrm{~kg} \mathrm{ha}^{-1} \mathrm{~N}, 45 \mathrm{~kg} \mathrm{ha}^{-1} \mathrm{P}$, and $40 \mathrm{~kg} \mathrm{ha}^{-1} \mathrm{~K}$. Then for all treatments, each plot was irrigated at an equal rate of $450 \mathrm{~m}^{3} \mathrm{hm}^{-2}$ biweekly until the late August. Moreover, plant protection was applied when needed based on the traditional agronomic management. Aboveground plant biomass was sampled at random from a $1 \mathrm{~m}^{2}$ location in each plot. The plant samples were dried at $65^{\circ} \mathrm{C}$ for $48 \mathrm{~h}$ and then weighed.

\subsection{Laboratory Experiments for Soil Columns}

In this section, we sampled the undisturbed soil with $52 \mathrm{~mm}$ high and $70 \mathrm{~mm}$ in diameter from 10 to $20 \mathrm{~cm}$ deep layer of experimental lands. A stainless pipe with $6 \mathrm{~mm}$ diameter was applied to created artificial macropores from the soil column center. The air-dried soil samples from the same depth were pulverized and sieved, and then, cohesive particles less than $0.05 \mathrm{~mm}$ were removed. Finally, the remaining sand particles were incorporated into the gap, and the same amount was applied to obtain a consistent bulk density with soil column. 
In addition, column samples without artificial macropore were introduced as control. Each treatment was replicated three times under two salinized levels. All the soil columns were saturated from bottom with capillary rise for $30 \mathrm{~h}$. The saturated hydraulic conductivity (Ks) was measured with the constant head method [20] by a permeameter (TST-55, Nanjing Soil Instrument Co., Ltd., Nanjing City, China).

\subsection{Statistical Analysis}

The Statistical Product and Service Solutions (SPSS) analytical software package was used for all of the statistical analyses. Mean values were calculated for each of the measurements, and analysis of variance (ANOVA) was performed to the data sets to assess the treatment effects on the measured variables. When ANOVA indicated a significant $f$ value, multiple comparisons of mean values were made on the basis of the least significant difference $(L S D)$.

\section{Results}

\subsection{Saturated Hydraulic Conductivity of Soil Columns}

As presented in Figure 2, saturated hydraulic conductivity (Ks) was measured under two initial soil conditions. In comparison to the control group without macropore, AMSF method increased Ks by $268 \%(p=0.05)$ in mild salinization condition, and by $309 \%(p=0.05)$ in severe salinization condition. The results indicated an improvement for AMSF method on drainage capacity in soils. This could be explained by the replacement of cohesive particle, so that continuous macropores were generated between sand particles. Thus, water could be delivered preferentially into deeper soil layers through pores.

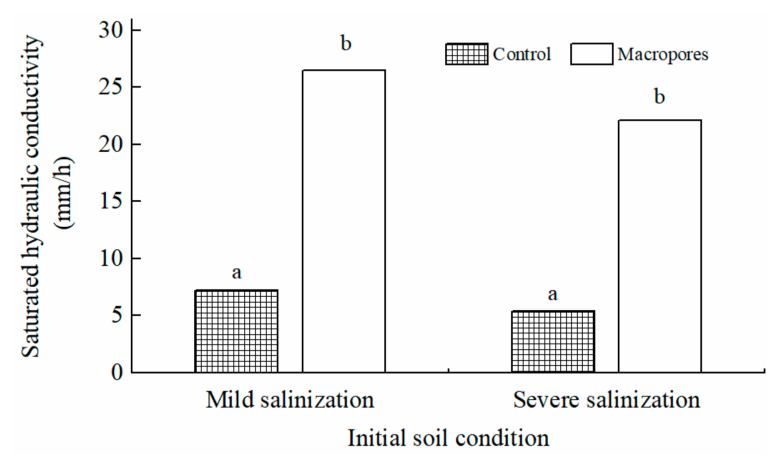

Figure 2. Saturated hydraulic conductivity (Ks) as affected by macropore treatment under two initial soil conditions. Control: soil columns without macropore treatment. Macropores: artificial macropores with sandy fillings (AMSF) treatment.

\subsection{Water Storage}

Figure 3 compares the mean water storage in 0 to $30 \mathrm{~cm}$ soil layer under two salinization levels, which was calculated within 25 days after irrigation. Gradually, mean water storage tended to decrease gradually from $125.7 \mathrm{~mm}$ to $76.4 \mathrm{~mm}$ with the passage of time. Meanwhile, mean values under severe salinization treatment were $2.2 \%$ to $8.6 \%$ higher than that of mild salinization condition.

For both initial salinization levels, there appeared to be a trend of decrease in mean water storage with the increasing of macropores depth (Figure 4). An overall decrease in stored water by $13.1 \%$ to $14.2 \%(p=0.05)$ was observed for $15 \mathrm{~cm}$ macropores depth treatment, as compared to the control group without macropore. 


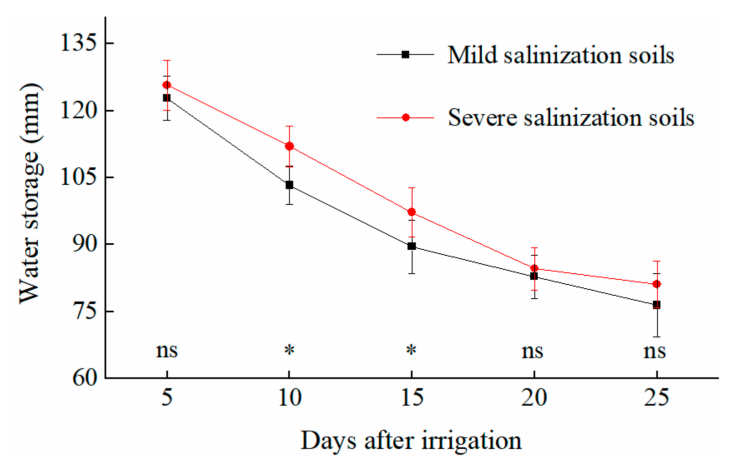

Figure 3. Mean water storage at top $30 \mathrm{~cm}$ under different salinization conditions without artificial macropores. Label "ns" means values within the same sampling time are not significantly different, and label "**" means values within the same sampling time are significantly different $(p=0.05)$.

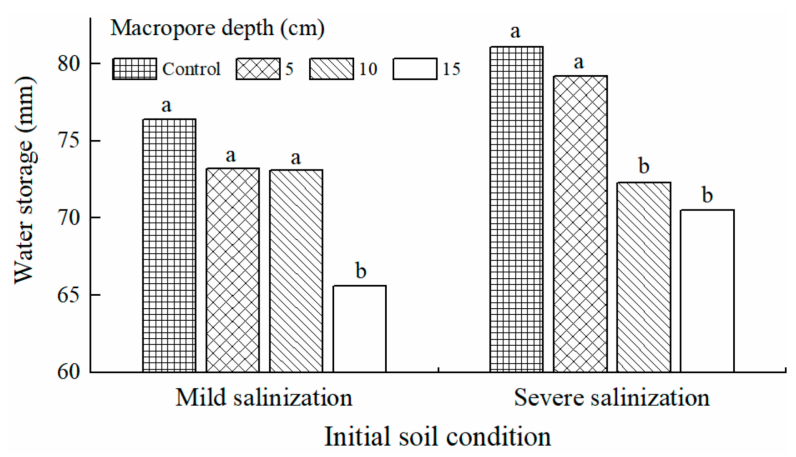

Figure 4. Mean water storage in top $30 \mathrm{~cm}$ soil layer 25 days after irrigation under different macropore depth treatments for artificial macropores with sandy fillings (AMSF) method. Control means soils without macropore. Mean values within same initial soil condition followed by different letters are significantly different $(p=0.05)$.

\subsection{Soil Salt Content}

As the water transport was accompanied by salt change, mean soil salt content under different macropore depth treatments was shown in Figure 5. For both of these two salinization levels, salt content appeared to decrease, firstly, and then increased with the increasing of soil depth. Specifically, in mild salinization condition, the salt content in top $20 \mathrm{~cm}$ for $10 \mathrm{~cm}$ macropore depth treatment was $1.2 \%$ to $15.5 \%$, and for $15 \mathrm{~cm}$ macropore depth treatment $5.8 \%$ to $21.8 \%$ less than that of control group $(p=0.05)$. Meanwhile, means in 20 to $60 \mathrm{~cm}$ soil layer under each macropore depth treatments were not significantly different $(p=0.05)$. Under severe salinization condition, the salt content with $10 \mathrm{~cm}$ macropore depth treatment was $1.5 \%$ to $4.7 \%$ less than control group throughout the $0-30 \mathrm{~cm}$ soil layer. For $15 \mathrm{~cm}$ macropore depth treatment, the salt content was $2.3 \%$ to $9.8 \%$ less than that of control group throughout the $0-30 \mathrm{~cm}$ soil layer.

\subsection{Soil Desalinization}

Mean salt storage to the depth of $30 \mathrm{~cm}$ for different macropore depth treatments was calculated in Table 3, in order to compare the effect of AMSF method on soil desalinization. The mean total salt appeared to be a similar tendency of decrease for both initial salinization conditions with the increasing of macropore depth, i.e., the order of means was $15 \mathrm{~cm}<10 \mathrm{~cm}$ $<5 \mathrm{~cm}<0 \mathrm{~cm}$ macropore depth treatment. 

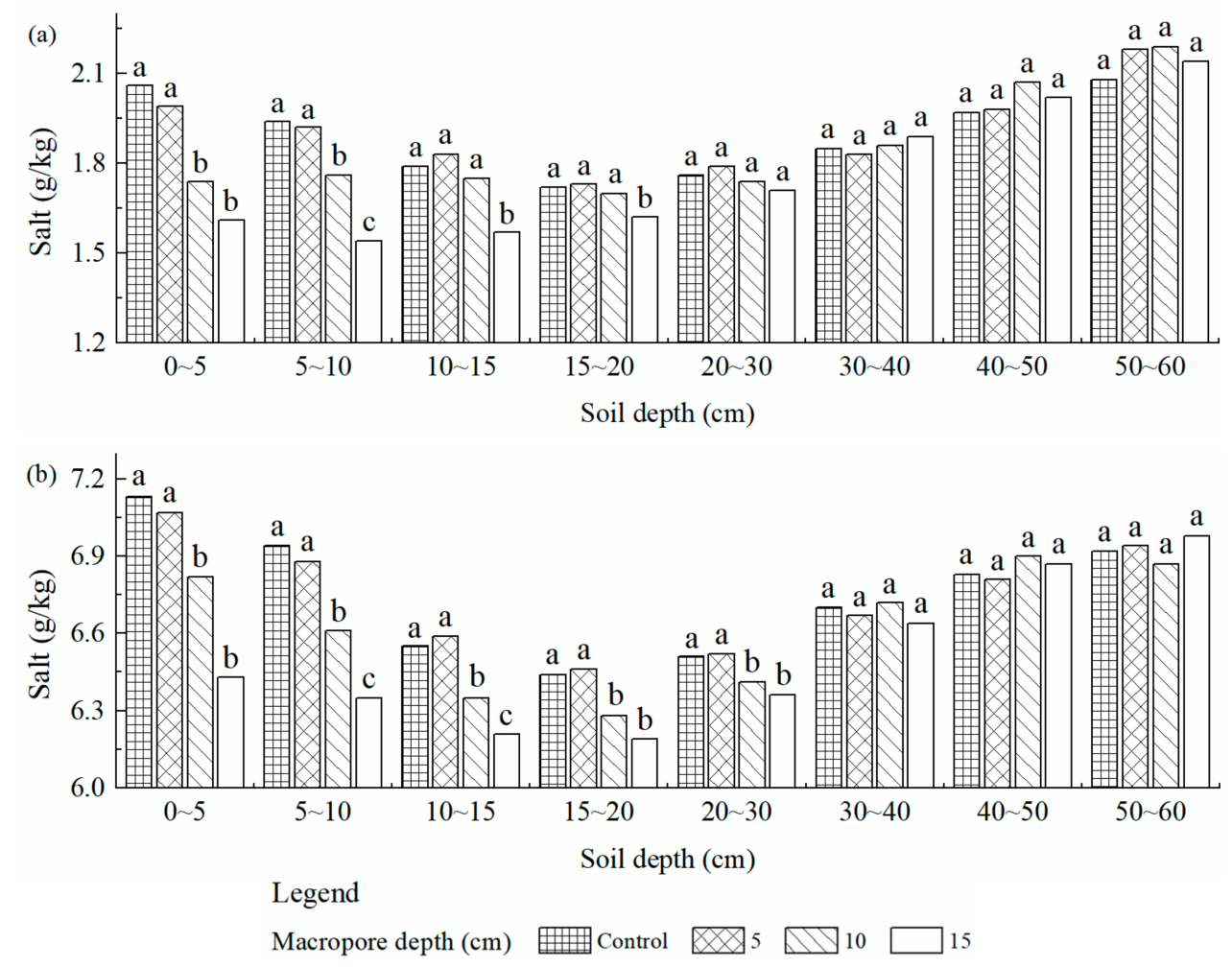

Figure 5. Mean soil salt content to the depth of $60 \mathrm{~cm} 25$ days after irrigation under different macropore depth treatments for artificial macropores with sandy fillings (AMSF) method. (a) Initial soil condition of mild salinization; (b) initial soil condition of severe salinization. Control means soils without macropore. Mean values within same soil profile followed by different letters are significantly different $(p=0.05)$.

Table 3. Mean total salt and total desalinization in top $30 \mathrm{~cm}$ soil layer after 25 days of irrigation for different macropore depth treatments for artificial macropores with sandy fillings (AMSF) method. Control means soils without macropore. Mean Values within a column followed by different letters are significantly different $(p=0.05)$.

\begin{tabular}{cccc}
\hline Initial Soil Condition & Macropore Depth $\mathbf{( c m )}$ & Total Salt $\left(\mathbf{g ~ m}^{\mathbf{2}}\right)$ & Total Desalinization $\left(\mathbf{g ~ m}^{-2}\right)$ \\
\hline & control & $766.6 \mathrm{a}$ & $50.0 \mathrm{c}$ \\
Mild salinization & 5 & $760.1 \mathrm{a}$ & $56.5 \mathrm{c}$ \\
& 10 & $724.9 \mathrm{~b}$ & $91.7 \mathrm{~b}$ \\
& 15 & $678.3 \mathrm{c}$ & $138.3 \mathrm{a}$ \\
\hline \multirow{3}{*}{ Severe salinization } & control & $2785.6 \mathrm{a}$ & $159.9 \mathrm{c}$ \\
& 5 & $2769.8 \mathrm{a}$ & $175.6 \mathrm{c}$ \\
& 10 & $2702.2 \mathrm{~b}$ & $243.3 \mathrm{~b}$ \\
& 15 & $2634.1 \mathrm{c}$ & $311.4 \mathrm{a}$ \\
\hline
\end{tabular}

Total desalinization in top $30 \mathrm{~cm}$ soil profile was determined by the difference in total salt before irrigation and after 25 days of irrigation. More specifically, in a $1200 \mathrm{~m}^{3} \mathrm{ha}^{-1}$ irrigation event, under mild salinization condition, $10 \mathrm{~cm}$ and $15 \mathrm{~cm}$ macropore depth treatments reduced total salt by 41.7 and $88.3 \mathrm{~g} \mathrm{~m}^{-2}$, and accordingly increased total desalinization by $83.5 \%$ and $176.6 \%$ significantly ( $p=0.05)$, respectively, as compared to control group without macropore. Meanwhile, the total desalinization under severe salinization condition with $\geq 10 \mathrm{~cm}$ macropore depth treatments were $52.1 \%$ to $94.7 \%(p=0.05)$ higher than control group.

\subsection{Plant Biomass}

Figure 6 compares the aboveground plant biomass of alfalfa under different macropore depth treatments for AMSF method. After 2 months of growth, AMSF method harvested more plant biomass. The biomass was $20.8 \%$ higher under $15 \mathrm{~cm}$ macropore depth treat- 
ment than that in control group $(p=0.05)$. Moreover, more alfalfa biomass was observed under mild salinized level as compared with severe salinized level.

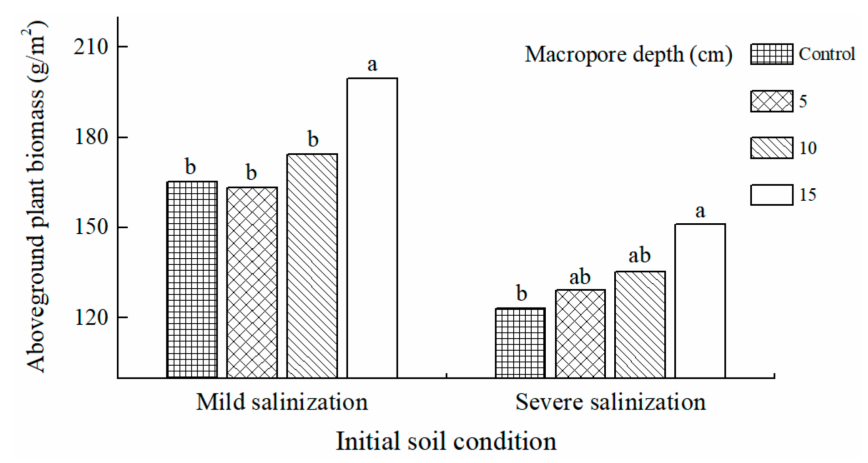

Figure 6. Aboveground plant biomass of alfalfa under different macropore depth treatments for artificial macropores with sandy fillings (AMSF) method. Control means soils without macropore. Mean values within same initial soil condition followed by different letters are significantly different $(p=0.05)$.

\section{Discussion}

\subsection{Salt Affects Water Movement}

It was reported that the macropores worked as prior water flow channels, which stimulated infiltration to deeper profile, but the empty macroporous structure is difficult to maintain. Based on the above, authors incorporated sandy material into artificial macropores to stabilize the structure [21]. However, the role of sand grains sieved from experimental soil in water transport has not been well analyzed. In addition, the salinity in coastal lands fluctuated periodically due to the incursion of seasonal tidal activity and monsoons [22]. In fact, the domestic coastal saline soils, within west Bohai Gulf, are highly argillaceous with poor permeability. Particularly from May to September, the salt accumulation near surface is severe because of high temperature and strong evapotranspiration, making the soils complicated to restore [23]. Therefore, experimental design in current research differed extremely from the previous ones. Firstly, soil column experiments were conducted to elucidate the roles of sandy particles in enhancing drainage capacity, in which silt and clay were removed from the column center. Secondly, contrasting soils under two salinized levels were selected considering the fluctuation characteristics of salinity. In contrast, in the previous experiments, soils were exposed to slight salinized environments throughout the monitoring stages (i.e., $2.4 \mathrm{~g} \mathrm{~kg}^{-1}$ of salt, Zhang et al. [21]). Moreover, irrigation for the total plots were carried out simultaneously to ensure the same climate parameters such as temperature, evaporation, and wind, and to thereby simplify measuring process. Finally, a seasonal observation for alfalfa, 2 months approximately, was introduced to investigate its potential significance.

In present irrigation events, 25-day observation was conducted. This short-term monitoring came for the following reasons. Primarily, 25 days after irrigation, water movement entered a relatively stable status, and the moisture in each soil layer appeared to be close to the unirrigated farmland area around the study region. Moreover, it was reported that salt accumulating up occurred about 20 days after irrigation under similar soil texture [17]. Although Ju et al. [24] demonstrated that salt accumulation occurred in the 60th day after irrigation by field crop experiments. This different result could be explained by the 3-time continuous irrigation which made the salt maintain at low values in the initial 40 days of experiments, and the influence of root on salt may also delayed the accumulation process.

Higher soil water holding capacity was measured with the increasing of salt content under similar soil texture. This relevant tendency was consistent with the results of Feng and Yang [25]. However, this correlation between salt and improved water environment could not be concluded because the enhanced water holding capacity was relevant to soil 
hygroscopic coefficient, which could hardly verify the increase in available water. $\mathrm{Li}$ [26] found that soil hygroscopic coefficient increased to more than $17.9 \%$ when salt content was over $7.6 \mathrm{~g} \mathrm{~kg}^{-1}$. Meanwhile, with the increasing of soil salt content, wilting coefficient increased [27], and accordingly, the soil available water absorbed by crops was decreased. Therefore, although salt increased the soil water content, the field water environment was not improved because crop water stress was also exacerbated. Subsequent observations for alfalfa verified the above inference, because alfalfa biomass under severe salinized level was less than that of mild salt condition.

The salts precipitated at surface would be dissolved and then washed below the rooting zone. Results here demonstrated a positive effect on leaching soil particles with freshwater, as $\geq 50 \mathrm{~g} \mathrm{~m}^{-2}$ total salt in top $30 \mathrm{~cm}$ soil layer was flushed into deeper profile. In general terms, extra input with freshwater can dilute the liquid water which contains soluble salt and drive them downward during infiltrating.

\subsection{Artificial Macropores Enhances Desalinization and Plant Yield}

Soil column experiments showed a significant improvement for Ks by more than $260 \%$ when cohesive particles were removed. This result confirmed the key role of macropore in water movement, especially under saturated condition. Meanwhile, this result also provided a basis for the promotion of water infiltration and solute migration in flood irrigation events.

Salt toxicity is a major restrictive element in soil structural degradation characterized by high exchangeable sodium percentage (ESP), which will worsen soil fertility and water permeability extremely $[28,29]$. AMSF method in irrigation experiments showed some benefits for improving soil leaching in the upper $30 \mathrm{~cm}$ soil profile, as well as environmental improvement for rooting zone. These positive results benefited from more water infiltrating into the deeper layer. Artificial macropores provided continuous pores, which introduced flow channels in the soil. Another possible reason for this would come from the eliminated surface flooding [30], which reduced the tendency of generating secondary salinization resulting from soil evapotranspiration. Secondary salinization or anthropogenic salinization is the result of improper water input from human activities such as excessive irrigation and longstanding flooding [31,32]. More alfalfa biomass was observed, which may result from the enhanced soil leaching to deeper layer, as a lower salinized environment can alleviate the salt stress on crops.

Furthermore, salt crust, i.e., crystals or efflorescence was reported to formed at soil surface when salt content exceeded its solubility. This hydrological phenomenon could maintain the underlying soil wetter and allow more salt accumulation below the crust. However, it was also a complicated process and required long-term continuous monitoring. In present study, no salt crust was detected throughout the whole testing duration, probably because the shorter monitoring time.

\subsection{Future Applications for Agriculture Practice in Salt-Affected Soils}

The accumulation of sodium chloride is a vital reason for salinization in coastal agricultural region [33]. Due to the filling of fine sand, the artificial macropore structure maintained effectively, and the salt redistribution for topsoil could be detected under 25-day observation. Irrigation experiments showed that total desalinization in top $30 \mathrm{~cm}$ soil profile with $\geq 10 \mathrm{~cm}$ macropore depth treatments for AMSF method were improved by more than $50 \%$ as compared to control group without artificial macropore.

In this study, we also focused on validating the feasibility of sandy materials in agricultural farming. In salt-affected soils, fertilizers and amendments are the most common agronomic resources, which would be applied into plough layer in the form of physical particles. Based on the proven hypothesis, we have reasons to infer that water and salt environment can be further improved by optimizing particle composition ratio and application strategy for amendment, and thereby stimulate crop performance. 
In general terms, it is essential to establish an optimized management method for salt-affected farmland, considering the interaction between water input, plant tolerance and agronomic measures. There are two unanswered questions that need to be completed in subsequent research. Firstly, soil evaporation makes a vital role in water movement, and long-term monitoring is required to explain the role of evaporation in soil salt accumulation. Secondly, the study of AMSF method affecting soil properties and crop growth was not involved. It is necessary to apply the hypothesis to agriculture practice to deepen the research on soil amendment utilization. For example, whether farmers can obtain better rhizosphere environment by artificial macropores with amendment incorporation can be further discussed. Deeper insights into the effect of amendment's spatial distribution on response to the ionic migration and the potential values for particles size redesign in field crop experiments will probably contribute to the successful farming practice of our findings.

Importantly, the short-term observations described here about how AMSF method can affect salt condition provide an exploration demonstration to pursue these studies with the ultimate goal of incorporating new application approaches for amendment into coastal salt-affected lands of northern China.

\section{Conclusions}

In this study, artificial macropores with sandy fillings (AMSF) method was proposed to improve topsoil leach. Soil column experiments showed a significant improvement of saturated hydraulic conductivity (Ks) by more than $260 \%$ under AMSF method. In farmlands, freshwater irrigation was conducted, and 25-day sampling showed that $10 \mathrm{~cm}$ or more macropore depth treatments of AMSF method enhanced total desalinization by $52.1 \%$ to $176.6 \%$ in $0-30 \mathrm{~cm}$ soil layer, in comparison to the control group without artificial macropore. Subsequent observations for alfalfa showed higher plant biomass by $20.8 \%$ under $15 \mathrm{~cm}$ macropore depth.

Despite the evidence mentioned above demonstrating that AMSF method enhanced downward movement of water and salts, salt accumulation has also resulted from some other aspects of ecosystem such as climatic change and man-made agricultural activities. Therefore, further studies will be needed to define how to combine AMSF method or grain-size optimizing for amendment with crop cultivation best and more microscopic information of soil physicochemical properties.

Author Contributions: All authors contributed to this study; Y.Z., conceptualization, methodology, software, data curation, writing-original draft preparation; R.Z., resources, visualization, funding acquisition, validation; X.X., formal analysis, project administration; B.Z., investigation, supervision, writing - review and editing. All authors have read and agreed to the published version of the manuscript.

Funding: This research was funded by Interdisciplinary Project of Yangzhou University Crop Science Special Zone (yzuxk202007), the Natural Science Foundation of the Jiangsu Higher Education Institutions (20KJB416008), the Key Research and Development Program of Jiangsu Province (BE2020319), the Jiangsu Modern Agricultural Machinery Equipment and Technology Demonstration and Promotion Project (NJ2020-17), the Program for Innovative Research Team in Ministry of Education of China (IRT13039), the Taizhou Science and Technology Infrastructure Program (TN201913), and the Nanjing Science and Technology Program (201805062).

Institutional Review Board Statement: Not applicable.

Informed Consent Statement: Not applicable.

Data Availability Statement: Data contained within the article.

Acknowledgments: The authors gratefully acknowledge that this research was supported by Interdisciplinary Project of Yangzhou University Crop Science Special Zone (yzuxk202007), the Natural Science Foundation of the Jiangsu Higher Education Institutions (20KJB416008), the Key Research and Development Program of Jiangsu Province (BE2020319), the Jiangsu Modern Agricultural Machinery 
Equipment and Technology Demonstration and Promotion Project (NJ2020-17), the Program for Innovative Research Team in Ministry of Education of China (IRT13039), the Taizhou Science and Technology Infrastructure Program (TN201913), and the Nanjing Science and Technology Program (201805062). The authors also thank all the anonymous reviewers for their constructive suggestions on this article.

Conflicts of Interest: The authors declare no conflict of interest.

\section{References}

1. Rengasamy, P. World salinization with emphasis on Australia. J. Exp. Bot. 2006, 57, 1017-1023. [CrossRef] [PubMed]

2. Wu, J.; Li, P.; Qian, H.; Fang, Y. Assessment of soil salinization based on a low-cost method and its influencing factors in a semi-arid agricultural area, northwest China. Environ. Earth Sci. 2014, 71, 3465-3475. [CrossRef]

3. Luo, S.; Wang, S.; Tian, L.; Shi, S.; Xu, S.; Yang, F.; Li, X.; Wang, Z.; Tian, C. Aggregate-related changes in soil microbial communities under different ameliorant applications in saline-sodic soils. Geoderma 2018, 329, 108-117. [CrossRef]

4. Liu, B.; Zhao, W.; Wen, Z.; Yang, Y.; Chang, X.; Yang, Q.; Meng, Y.; Liu, C. Mechanisms and feedbacks for evapotranspirationinduced salt accumulation and precipitation in an arid wetland of China. J. Hydrol. 2019, 568, 403-415. [CrossRef]

5. Zhang, X.; Shao, L.; Sun, H.; Chen, S.; Wang, Y. Incorporation of Soil Bulk Density in Simulating Root Distribution of Winter Wheat and Maize in Two Contrasting Soils. Soil Sci. Soc. Am. J. 2012, 76, 638-647. [CrossRef]

6. Beven, K.; Germann, P. Macropores and water flow in soils. Water Resour. Res. 1982, 18, 1311-1325. [CrossRef]

7. Flury, M. Experimental Evidence of Transport of Pesticides through Field Soils-A Review. J. Environ. Qual. 1996, 25, 25-45. [CrossRef]

8. Mori, Y.; Iwama, K.; Maruyama, T.; Mitsuno, T. Discriminating the influence of soil texture and management-induced changes in macropore flow using soft X-rays. Soil Sci. 1999, 164, 467-482. [CrossRef]

9. Saravanathiiban, D.S.; Kutay, M.E.; Khire, M.V. Effect of macropore tortuosity and morphology on preferential flow through saturated soil: A Lattice Boltzmann study. Comput. Geotech. 2014, 59, 44-53. [CrossRef]

10. Mori, Y.; Hirai, Y. Effective Vertical Solute Transport in Soils by Artificial Macropore System. J. Hazard. ToxicRadioact. Waste 2014, 2, 1-7. [CrossRef]

11. Mori, Y.; Suetsugu, A.; Matsumoto, Y.; Fujihara, A.; Suyama, K. Enhancing bioremediation of oil-contaminated soils by controlling nutrient dispersion using dual characteristics of soil pore structure. Ecol. Eng. 2013, 51, 237-243. [CrossRef]

12. Atkinson, J.L.; McCarty, L.B.; Bridges, W.C., Jr. Effect of Core Aerification Frequency, Area Impacted, and Topdressing Rate on Turf Quality and Soil Physical Properties. Agron. J. 2012, 104, 1710-1715. [CrossRef]

13. Shah, S.B.; Miller, J.L.; Basden, T.J. Mechanical aeration and liquid dairy manure application impacts on grassland runoff water quality and yield. Trans. ASAE 2004, 47, 777-788. [CrossRef]

14. Datta, A.; Yeluripati, J.B.; Nayak, D.R.; Mahata, K.R.; Santra, S.C.; Adhya, T.K. Seasonal variation of methane flux from coastal saline rice field with the application of different organic manures. Atmos. Environ. 2013, 66, 114-122. [CrossRef]

15. Lv, Z.Z.; Liu, G.M.; Yang, J.S.; Zhang, M.M.; He, L.D.; Shao, H.B.; Yu, S.P. Spatial variability of soil salinity in Bohai Sea coastal wetlands, China: Partition into four management zones. Plant Biosyst. 2013, 147, 1201-1210. [CrossRef]

16. Mori, Y.; Fujihara, A.; Yamagishi, K. Installing artificial macropores in degraded soils to enhance vertical infiltration and increase soil carbon content. Prog. Earth Planet. Sci. 2014, 1, 30. [CrossRef]

17. Li, W.; Zheng, Z.; Li, T.; Yu, H.; Zeng, L. Effects of salt ions transport on different levels of secondary salinization soil under greenhouse irrigation. Trans. Chin. Soc. Agric. Mach. 2011, 42, 92-99.

18. He, J.; Wang, Q.; Li, H.; Lu, C.; Qiao, X.; Lu, Z. Effects of no-till opening seedbed on crop growth in annual double cropping areas in northern China. Trans. Chin. Soc. Agric. Mach. 2013, 44, 50-56.

19. Du, S.; Yu, J.; Geng, G.; Li, M.; Bai, G. Effects of planting hole sealing methods on soil moisture, temperature, salinity and survival rate of tomato seedling. Trans. Chin. Soc. Agric. Eng. 2012, 28, 110-116.

20. Klute, A. Methods of Soil Analysis: Part 1-Physical and Mineralogical Methods; Soil Science Society of America, American Society of Agronomy: Madison, WI, USA, 1986.

21. Zhang, Y.; Li, H.; Hu, H.; Wang, X.; Chen, W. Punching and filling sand method increasing water infiltration and desalting rate of saline-alkali soil under flooding irrigation. Trans. Chin. Soc. Agric. Eng. 2017, 33, 76-83.

22. Sun, J.; Kang, Y.; Wan, S.; Hu, W.; Jiang, S.; Zhang, T. Soil salinity management with drip irrigation and its effects on soil hydraulic properties in north China coastal saline soils. Agric. Water Manag. 2012, 115, 10-19. [CrossRef]

23. Freedman, A.; Gross, A.; Shelef, O.; Rachmilevitch, S.; Arnon, S. Salt uptake and evapotranspiration under arid conditions in horizontal subsurface flow constructed wetland planted with halophytes. Ecol. Eng. 2014, 70, 282-286. [CrossRef]

24. Ju, L.; Wang, Q.; Wang, L.; Shi, X. Effects of irrigation amounts on yield of winter wheat and distribution characteristics of soil water-salt in semi-arid region. Trans. Chin. Soc. Agric. Eng. 2007, 23, 86-90.

25. Feng, Y.; Yang, J. Correlation Between Soil Water Retention Capability and Soil Salt Content. Pedosphere 2000, 10, $275-280$.

26. Li, X.G. Hygroscopic coefficient and wilting point of salt-affected soils in jingdian irrigation zone, gansu. Acta Pedol. Sin. 2001, 38, 498-505.

27. Li, X.; Cao, J.; Li, F. Influence of salinity, sodicity, and organic matter on some physical properties of salt-affected soils. Chin. J. Soil Sci. 2004, 35, 64-72. 
28. Dai, L.Y.; De Yin, K.; Zhang, Y.X.; Yu, C.Q.; Li, M.; Du, J.D. Screening and analysis of soda saline-alkali stress induced up-regulated genes in sugar sorghum. Maydica 2016, 61, 1-9.

29. Chaganti, V.N.; Crohn, D.M. Evaluating the relative contribution of physiochemical and biological factors in ameliorating a saline-sodic soil amended with composts and biochar and leached with reclaimed water. Geoderma 2015, 259, 45-55. [CrossRef]

30. Taylor, M.; Krüger, N. Changes in salinity of a clay soil after a short-term salt water flood event. Geoderma Reg. 2019, 19, 1-8. [CrossRef]

31. Tan, S.; Wang, Q.; Xu, D.; Zhang, J.; Shan, Y. Evaluating effects of four controlling methods in bare strips on soil temperature, water, and salt accumulation under film-mulched drip irrigation. Field Crop. Res. 2017, 214, 350-358. [CrossRef]

32. Zalacáin, D.; Martínez-Pérez, S.; Bienes, R.; García-Díaz, A.; Sastre-Merlín, A. Salt accumulation in soils and plants under reclaimed water irrigation in urban parks of Madrid (Spain). Agric. Water Manag. 2019, 213, 468-476. [CrossRef]

33. Roy, K.; Sasada, K.; Kohno, E. Salinity status of the 2011 Tohoku-oki tsunami affected agricultural lands in northeast Japan. Int. Soil Water Conserv. Res. 2014, 2, 40-50. [CrossRef] 